\title{
The Influence of Sleep Apnea on 24-Hour and Nocturnal ECG and Blood Pressure Parameters in Patients with Acute Heart Failure
}

\author{
Attila Frigy $^{a} \quad$ Irma Varga $^{b}$ Zoltán Fogarasib ${ }^{b}$ Boglárka Belényi ${ }^{b} \quad$ Ildikó Kocsis $^{b}$ \\ a Department of Internal Medicine IV, University of Medicine and Pharmacy of Tirgu Mures, Tirgu Mures, Romania; \\ ${ }^{\mathrm{b}}$ Department of Cardiology, Clinical County Hospital Mures, Tirgu Mures, Romania
}

\section{Significance of the Study}

- This study investigated the influence of sleep apnea (SA) on 24-hour ECG and blood pressure (BP) parameters in stabilized acute heart failure patients. The results confirm the negative effects of severe SA on BP behavior and arrhythmogenesis, reinforcing also the recommendation of complex routine monitoring of these patients for therapeutic and prognostic reasons before hospital discharge.

\section{Keywords}

Heart failure $\cdot$ Sleep apnea $\cdot$ Arrhythmia $\cdot$ Blood pressure monitoring

\footnotetext{
Abstract

Objective: To investigate the influence of sleep apnea (SA) on ECG and blood pressure (BP) monitoring parameters in patients with acute heart failure (AHF). Methods: A total of 51 hospitalized patients with AHF (13 women, 38 men, mean age 60.8 years) underwent 24 -hour combined monitoring of ECG and BP and SA testing before discharge. Heart rhythm (mean heart rate, arrhythmias, pauses, QT interval, heart rate variability) and BP (mean systolic and diastolic values, variability, circadian variation) parameters were obtained for the whole day and for nighttime (22:00-06:00). Depending on SA severity, the patients were divided into two groups (respiratory event index, REl, $<15 / h$ and $\geq 15 / h$ ). Comparisons
}

of parameters between the two groups were performed using t test and $x^{2}$ test (alpha $<0.05$ for significance). Results: $A$ total of 29 (56.9\%) patients had REI $\geq 15 / \mathrm{h}$. In this group, the systolic and diastolic BP values (24-hour and nighttime) were significantly higher $(p<0.05)$. BP variability did not differ, and a markedly blunted circadian variation of both the systolic and diastolic values was observed. In the group with REI $\geq 15 / h$, we found a higher nocturnal versus diurnal mean heart rate ratio $(p=0.046)$ and a greater occurrence of nocturnal versus diurnal ventricular premature beats ( $p=$ 0.0098). Conclusion: The presence of significant SA was found to influence the BP values and nocturnal ventricular ectopy in patients with stabilized AHF. SA, 24-hour ECG, and BP monitoring could provide important information with potential impact on patient management.

(C) 2018 The Author(s)

Published by S. Karger AG, Basel

\begin{tabular}{|c|c|c|}
\hline KARGER & $\begin{array}{l}\text { (0) } 2018 \text { The Author(s) } \\
\text { Published by S. Karger AG, Basel }\end{array}$ & $\begin{array}{l}\text { Karger } \\
\text { Open access }\end{array}$ \\
\hline $\begin{array}{l}\text { E-Mail karger@karger.com } \\
\text { www.karger.com/mpp }\end{array}$ & $\begin{array}{l}\text { This is an Open Access article licensed } y \\
\text { Attribution-NonCommercial-4.0 Intern } \\
\text { (http://www.karger.com/Services/Open } \\
\text { the online version of the article only. } \\
\text { commercial purposes requires written p }\end{array}$ & $\begin{array}{l}\text { er the Creative Commons } \\
\text { onal License (CC BY-NC) } \\
\text { essLicense), applicable to } \\
\text { age and distribution for } \\
\text { nission. }\end{array}$ \\
\hline
\end{tabular}

Attila Frigy, $\mathrm{MD}, \mathrm{PhD}$

Department of Internal Medicine IV

University of Medicine and Pharmacy of Tirgu Mures, Gh. Marinescu str. 1

RO-540103 Tirgu Mures (Romania)

E-Mail afrigy68@gmail.com 


\section{Introduction}

Acute heart failure (AHF) is a clinical entity with important prognostic and disease management implications. Thus, independently of the actual clinical scenario, beyond the acute management, there are some compulsory tasks which have to be completed on every patient hospitalized with AHF: (1) establishing the cardiac substrate and the trigger factor(s) of decompensation, (2) rethinking chronic management, including the need for invasive interventions (e.g., coronary, valvular, etc.) and implantable devices, (3) prognostic evaluation using multiple parameters (clinical and laboratory data, biomarkers, echocardiographic and Holter-derived data, etc.), (4) diagnosis and treatment (strategy) of noncardiac comorbidities, and (5) reinforcing treatment adherence and integrated patient monitoring $[1,2]$.

Generally, identification and efficient control of noncardiac comorbidities, e.g., chronic obstructive pulmonary disease, anemia, iron deficiency, diabetes, sleep apnea (SA), etc., could improve significantly the quality of life and prognosis of patients with heart failure (HF) [1].

In the above context, patients admitted to our clinic with AHF when already in stable clinical condition, undergo 24-hour combined ambulatory monitoring (Holter ECG and ambulatory blood pressure monitoring, ABPM) and SA testing before discharge. The former is performed primarily for arrhythmia, ischemia, and blood pressure (BP) profile analysis, and based on monitoring results, for prognostic evaluation. The aim of SA testing is the diagnosis and quantification of comorbid SA, a condition frequently associated with $\mathrm{HF}$, the HF-SA relationship being bidirectional, with known impact on quality of life, prognosis, and treatment [3].

Keeping in mind the effects of SA on heart rhythm and BP behavior, with potential practical implications, and the relatively limited literature regarding this subject in $\mathrm{HF}$, we investigated the influence of SA on 24-hour and nocturnal Holter ECG and ABPM parameters in patients with AHF. Our main goal was to demonstrate a deleterious effect of SA, providing new arguments for routine SA monitoring in this setting.

\section{Materials and Methods}

\section{Patient Population}

A total of 51 consecutive cases ( 13 women, 38 men, mean age 60.8 years) were included in the study, from the patients hospitalized with AHF in the Department of Cardiology of the Clini- cal County Hospital Mures, Tirgu Mures, Romania. AHF was a manifestation of acute decompensated chronic HF in all patients. At admission, the patients signed the general consent form used in our institution, agreeing to anonymous data collection for scientific purposes. Approval of the local Ethics Committee was obtained for confidential collection and processing of data. The exclusion criteria were: severe hemodynamic instability during hospitalization, significant insomnia, and chronic treatment for obstructive SA with continuous positive airway pressure (CPAP) therapy. During admission, the patients received the usual care applied to patients with AHF in our department, including common diagnostic and therapeutic procedures.

\section{In-Hospital SA Testing}

At the end of hospital admission, when already in stable clinical condition, the patients underwent overnight polygraphy (Stardust II ${ }^{\circledR}$, Alice NightOne ${ }^{\circledR}$; Philips Respironics, USA - type III monitoring devices) for assessing the presence, type, and severity of SA. The device was applied at bedtime by a member of the medical staff (physician or nurse), and during nighttime the properly trained night shift nurse supervised the registration. Monitoring consisted of recording of the following six signals: nasal airflow, oxygen saturation, heart rate, thoracic movements, body position, and snoring. The recordings were edited and corrected manually. The episodes of apnea and hypopnea were defined according to the criteria of the American Academy of Sleep Medicine. The overall type of SA was labeled as central or obstructive depending on the predominance (more than $50 \%$ of all episodes) of the central or obstructive events. Central events also included the periods with Cheyne-Stokes respiration, which were defined as at least three consecutive cycles of respiration with crescendo-decrescendo pattern interrupted by central hypopnea or apnea. The level of severity was expressed using the respiratory event index (REI) - the number of hypopneas and apneas/registration hours $[4,5]$. Depending on the REI values $(<15 / \mathrm{h}$ and $\geq 15 / \mathrm{h})$, the patients were divided into two groups to evaluate the influence of SA on Holter-ABPM parameters.

\section{Combined 24-Hour Holter ECG and ABPM}

The monitoring was performed together with SA testing, using the EC-3H/ABP Cardiospy ${ }^{\circledR}$ system (Labtech Ltd., Hungary) capable of combined ECG and BP recordings.

Before final analysis, the ECG registrations were edited for verification of template and elimination of artifacts. Then, the Holter ECG parameters (Table 1) were determined by the proprietary algorithm of the software. Special emphasis was placed on the study of nocturnal (22:00-06:00) heart rate, arrhythmias, and heart rate variability (HRV, time domain analysis, global and vagally mediated components) - parameters with a possible relationship to the presence of significant SA.

The automatic BP measurements were performed on the dominant arm of the subjects and were set at every 20 min during the day and at $30 \mathrm{~min}$ during nighttime (22:00-06:00). The patients were instructed about proper position of the arm and body (while awake) during measurements. During the review and analysis of $\mathrm{BP}$ values, artifacts were eliminated manually by an experienced examiner. The diverse ABPM parameters calculated (Table 2) also included those referring to BP variability. 
Table 1. Holter ECG parameters and their description

\begin{tabular}{|c|c|}
\hline Parameter & Description \\
\hline MHR & 24-hour mean heart rate (beats/min) \\
\hline NMHR & Nocturnal mean heart rate (beats/min) \\
\hline N/D MHR & Nocturnal/diurnal mean heart rate ratio \\
\hline VPB & 24-hour ventricular premature beats (\% of total beats) \\
\hline NVPB & Nocturnal ventricular premature beats (\% of nocturnal beats) \\
\hline $\mathrm{N} / \mathrm{D} \mathrm{VPB}>1$ & NVPB/diurnal ventricular premature beats $(\%)$ ratio $>1$ ( $n$ of patients) \\
\hline NVR/T & Nocturnal ventricular run or tachycardia ( $n$ of patients) \\
\hline $\mathrm{SVPB}^{\mathrm{a}}$ & 24-hour supraventricular premature beats (\% of total beats) \\
\hline NSVPB $^{\mathrm{a}}$ & Nocturnal supraventricular premature beats (\% of nocturnal beats) \\
\hline $\mathrm{N} / \mathrm{D}$ SVPB $>1^{\mathrm{a}}$ & NSVPB/diurnal supraventricular premature beats $(\%)$ ratio $>1$ ( $n$ of patients) \\
\hline $\mathrm{NSVR} / \mathrm{T}^{\mathrm{a}}$ & Nocturnal supraventricular run or tachycardia ( $n$ of patients) \\
\hline $\mathrm{NAF}^{\mathrm{a}}$ & Nocturnal atrial fibrillation ( $n$ of patients) \\
\hline NP & Nocturnal pause $>2,400 \mathrm{~ms}$ ( $n$ of patients) \\
\hline NQTlong & Nocturnal QTc max $>500 \mathrm{~ms}$ ( $n$ of patients) \\
\hline \multirow[t]{2}{*}{$\mathrm{SDNN}^{\mathrm{a}}$} & Standard deviation of normal (sinusal) RR intervals, for $24 \mathrm{~h}$ (ms) \\
\hline & Time domain parameter of global HRV \\
\hline $\mathrm{NSDNN}^{\mathrm{a}}$ & SDNN calculated for nighttime (ms) \\
\hline \multirow[t]{2}{*}{$\mathrm{rMSSD}^{\mathrm{a}}$} & Root mean square successive (normal, sinusal, RR intervals) difference, for $24 \mathrm{~h}$ (ms) \\
\hline & Time domain parameter of vagally mediated component of $H R V$ \\
\hline NrMSSD $^{\mathrm{a}}$ & rMSSD calculated for nighttime (ms) \\
\hline
\end{tabular}

${ }^{\text {a }}$ Not considered in patients with atrial fibrillation. HRV, heart rate variability.

Table 2. ABPM-derived parameters and their description

\begin{tabular}{ll}
\hline Parameter & Description \\
\hline MSBP & 24-hour mean systolic blood pressure $(\mathrm{mm} \mathrm{Hg})$ \\
MSBP $<110$ & 24-hour mean systolic blood pressure $<110 \mathrm{~mm} \mathrm{Hg}$ ( $n$ of patients) \\
NMSBP & Nocturnal mean systolic blood pressure $(\mathrm{mm} \mathrm{Hg})$ \\
NMSBP $<110$ & Nocturnal mean systolic blood pressure $<110 \mathrm{~mm} \mathrm{Hg}$ ( $n$ of patients) \\
MDBP & 24-hour mean diastolic blood pressure $(\mathrm{mm} \mathrm{Hg})$ \\
MDBP $<70$ & 24-hour mean diastolic blood pressure $<70 \mathrm{~mm} \mathrm{Hg}$ ( $n$ of patients) \\
NMDBP & Nocturnal mean diastolic blood pressure (mm Hg) \\
NMDBP $<70$ & Nocturnal mean diastolic blood pressure $<70 \mathrm{~mm} \mathrm{Hg}$ ( $n$ of patients) \\
SDSBP & 24-hour standard deviation of systolic blood pressure (mm Hg) \\
NSDSBP & Nocturnal standard deviation of systolic blood pressure (mm Hg) \\
SDDBP & 24-hour standard deviation of diastolic blood pressure (mm Hg) \\
NSDDBP & Nocturnal standard deviation of diastolic blood pressure (mm Hg) \\
DISBP & Diurnal index of systolic blood pressure (difference of diurnal and nocturnal mean \\
& systolic pressure/diurnal mean systolic pressure, \%) \\
DISBP $<10$ & Diurnal index of systolic blood pressure $<10 \%(n$ of patients) \\
DIDBP & Diurnal index of diastolic blood pressure (difference of diurnal and nocturnal mean \\
DIDBP $<10$ & diastolic pressure/diurnal mean diastolic pressure, \%) \\
\hline
\end{tabular}


Table 3. Characteristics of SA in the study population

\begin{tabular}{|c|c|c|c|c|c|}
\hline REI & $<5 / \mathrm{h}$ & $5-14.9 / \mathrm{h}$ & $15-29.9 / \mathrm{h}$ & $\geq 30 / \mathrm{h}$ & Total \\
\hline Patients, $n$ & $9(17.6 \%)$ & $13(25.4 \%)$ & $17(33.3 \%)$ & $12(23.5 \%)$ & 51 \\
\hline Predominantly obstructive, $n$ & $9(100 \%)$ & $10(77 \%)$ & $9(52.9 \%)$ & $6(50 \%)$ & $34(66.6 \%)$ \\
\hline Predominantly central, $n$ & 0 & $3(23 \%)$ & $8(47.1 \%)$ & $6(50 \%)$ & $17(33.3 \%)$ \\
\hline Patients in the two groups, $n$ & $22(43.1 \%)$ & & $29(56.9 \%)$ & & \\
\hline
\end{tabular}

Table 4. Main characteristics of the patient population with respect to the severity of SA

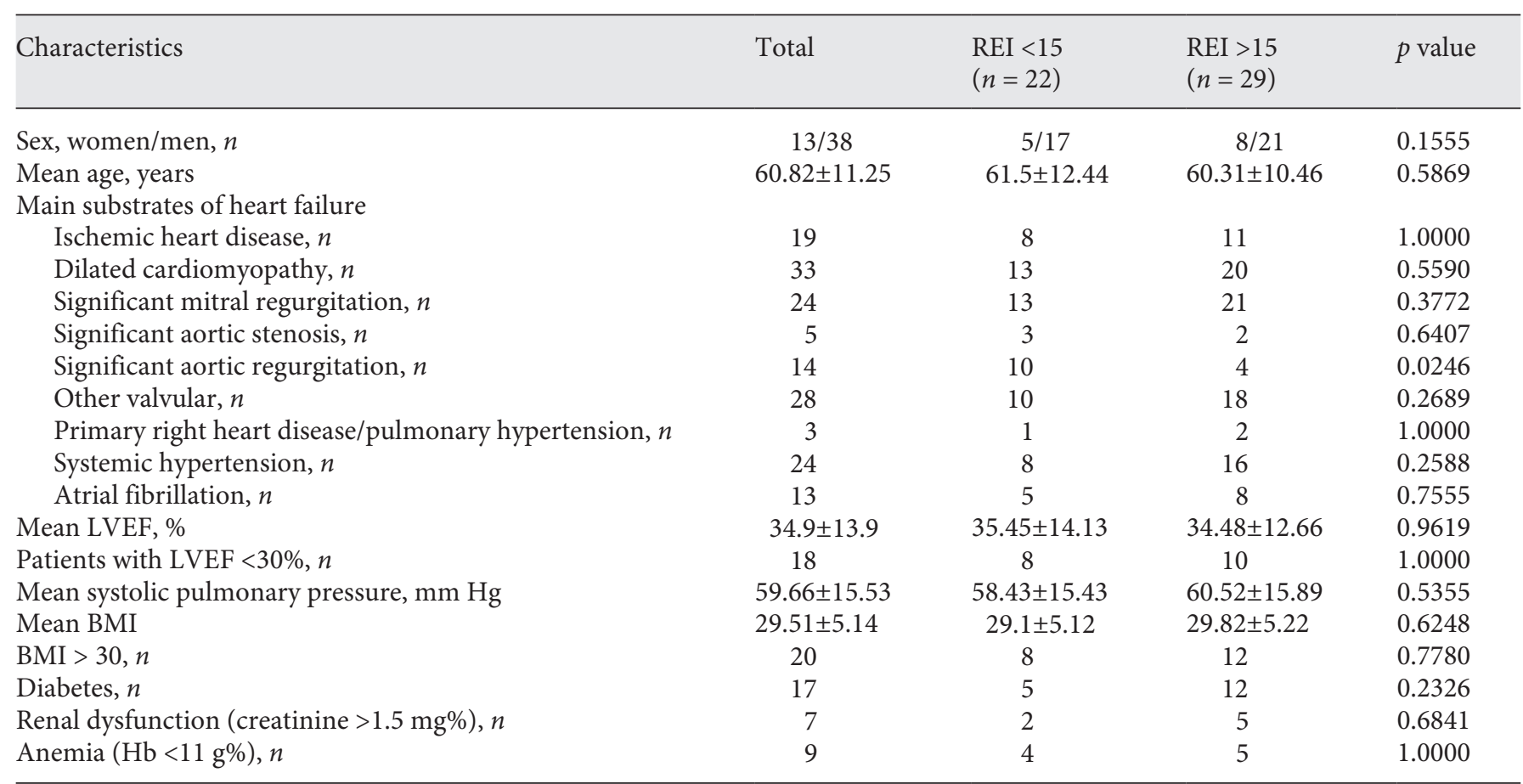

Values are mean \pm SD for continuous variables, except where otherwise indicated. LVEF, left ventricular ejection fraction.

\section{Statistics}

We used descriptive statistics for the characterization of patient population and the prevalence, type, and severity of SA. Comparisons between clinical characteristics, Holter ECG and ABPM parameters in the two groups ( $\mathrm{REI}<15 / \mathrm{h}$ and $\geq 15 / \mathrm{h}$ ) were performed using $t$ test (in the case of continuous variables) and $\chi^{2}$ test (in the case of categorical variables). Statistical significance was set at alpha $<0.05$ (statistical tool used - GraphPad InStat 3.0).

\section{Results}

Qualitative and quantitative data related to SA in the study population are presented in Table 3 . More than half (56.9\%) of the patients had significant SA (REI $\geq 15 / \mathrm{h}$ ), the obstructive form being predominant in the whole cohort, but the central form becoming more and more prevalent in the case of patients with REI $\geq 15 / h$. The main characteristics of the study population according to the severity of SA are presented in Table 4 . There were no significant differences except for the increased prevalence of significant aortic regurgitation in the group with the more severe form. Tables 5 and 6 present the ABPM and Holter ECG parameters in the two groups. We found significantly larger systolic and diastolic BP values (both for $24 \mathrm{~h}$ and nighttime) in the group with more severe SA $(p<0.05$, except for one parameter, MSBP $<110[p=$ $0.0964])$. BP variability parameters did not differ significantly in the two groups and a blunted circadian variation 
Table 5. Comparison of ABPM-derived parameters in the two groups

\begin{tabular}{lccc}
\hline Parameter & $\begin{array}{l}\text { REI }<15 \\
(n=22)\end{array}$ & $\begin{array}{l}\text { REI } \geq 15 \\
(n=29)\end{array}$ & $p$ value \\
\hline MSBP & $110.36 \pm 11.07$ & $118.89 \pm 17.74$ & 0.0444 \\
MSBP $<110$ & 13 & 10 & 0.0964 \\
NMSBP & $105.77 \pm 13.53$ & $117.92 \pm 19.7$ & 0.0178 \\
NMSBP $<110$ & 16 & 9 & 0.0047 \\
MDBP & $63.11 \pm 10.5$ & $72.58 \pm 9.22$ & 0.0016 \\
MDBP $<70$ & 17 & 10 & 0.0042 \\
NMDBP & $59.95 \pm 12.05$ & $69.88 \pm 9.81$ & 0.0031 \\
NMDBP $<70$ & 19 & 15 & 0.0155 \\
SDSBP & $11.91 \pm 3.93$ & $12.78 \pm 4.63$ & 0.4844 \\
NSDSBP & $9.3 \pm 4.17$ & $10.47 \pm 5.08$ & 0.3905 \\
SDDBP & $10.18 \pm 3.53$ & $11.18 \pm 3.7$ & 0.3382 \\
NSDBP & $8.24 \pm 4.12$ & $9.98 \pm 5.26$ & 0.2114 \\
DISBP & $5.44 \pm 4.72$ & $3.33 \pm 5.28$ & 0.2614 \\
DISBP $<10$ & 15 & 26 & 0.0789 \\
DIDBP & $7.79 \pm 7.02$ & $4.3 \pm 3.4$ & 0.1554 \\
DIDBP $<10$ & 13 & 19 & 0.7717 \\
\hline
\end{tabular}

Values are expressed as mean \pm SD or $n$.
Table 6. Comparison of Holter ECG parameters in the two groups

\begin{tabular}{lccc}
\hline Parameter & $\begin{array}{l}\text { REI }<15 \\
(n=22)\end{array}$ & $\begin{array}{l}\text { REI } \geq 15 \\
(n=29)\end{array}$ & $p$ value \\
\hline MHR & $73.27 \pm 11.25$ & $73.51 \pm 11.83$ & 0.5924 \\
NMHR & $69.68 \pm 11.72$ & $71.6 \pm 12.22$ & 0.5762 \\
N/D MHR & $0.91 \pm 0.06$ & $0.95 \pm 0.06$ & 0.0460 \\
VPB & $1.34 \pm 3.75$ & $1.04 \pm 1.26$ & 0.6969 \\
NVPB & $1.16 \pm 3.34$ & $2.7 \pm 8.46$ & 0.4345 \\
N/D VPB $>1$ & 4 & 16 & 0.0098 \\
NVR/T & 3 & 8 & 0.3116 \\
SVPB & $1.48 \pm 0.9$ & $1.36 \pm 1.73$ & 0.8705 \\
NSVPB & $1.3 \pm 0.76$ & $1.69 \pm 0.87$ & 0.5404 \\
N/D SVPB $>1^{\mathrm{a}}$ & 5 & 11 & 0.1972 \\
NSVR/T & 1 & 1 & 1.0000 \\
NAF $^{\mathrm{a}}$ & 3 & 2 & 0.6396 \\
NP $^{\mathrm{a}}$ & 1 & 2 & 1.0000 \\
NQTlong $_{\text {SDNN }}$ & 6 & 7 & 1.0000 \\
NSDNN $^{\mathrm{a}}$ & $62.64 \pm 28.46$ & $64.26 \pm 34.87$ & 0.9042 \\
rMSSD $^{\mathrm{a}}$ & $48.24 \pm 28.34$ & $60.57 \pm 32.25$ & 0.4978 \\
NrMSSD $^{\mathrm{a}}$ & $26.38 \pm 11.31$ & $44.83 \pm 13.44$ & 0.4190 \\
& $27.3 \pm 11.62$ & $51.77 \pm 15.96$ & 0.3506 \\
\hline
\end{tabular}

Values are expressed as mean $\pm \mathrm{SD}$ or $n .{ }^{\text {a }}$ Patients with atrial fibrillation were excluded.

els being the main mechanisms involved [9]. Several individual studies and meta-analyses have established the negative effects of SA on quality of life and prognosis of patients with HF $[10,11]$. Nocturnal (e.g., restless sleep, awakenings with choking) and diurnal (e.g., excessive daytime sleepiness) symptoms could seriously affect the everyday life of patients, and also have considerable effects on perception disease and adherence to therapy. SA could contribute to the progression of HF by various mechanisms: (1) autonomic imbalance characterized by sympathetic overactivity (caused mainly by the repetitive arousals), with its multiple consequences; (2) negative intrathoracic pressure during obstructive apneas, causing increased preload for the right heart and increased afterload for the left heart; (3) boosts of hypoxemia and myocardial ischemia, and (4) long-term myocardial damage caused by oxidative stress, hypercatecholemia, and chronic inflammation $[11,12]$.

Beyond its immediate practical value, SA testing during hospital admission has prognostic importance too, as the presence of significant SA is independently related to postdischarge mortality and hospital readmissions [13, 14].

In HF patients, heart rate, rhythm, and $\mathrm{BP}$ values and their variations are determined primarily by the current 
hemodynamic status, together with cardiac autonomic control (the latter being in close relationship with the former). These factors could be influenced by the multiple negative effects of SA. Higher values and blunted circadian variations (lack of physiological decrease during nighttime) of BP are known phenomena associated with significant SA in normal and hypertensive subjects. The best example in this regard is resistant hypertension associated with severe forms of (mainly obstructive) SA in the majority of cases, with a decreased diurnal index as a rule [15].

The ABPM results of our patients, with already stabilized AHF, revealed significantly higher BP values (both diurnal and nocturnal, systolic and diastolic) in the group with more severe SA; however, the mean BP values were relatively low in both groups. The latter phenomenon could be explained by the decreased cardiac output, together with the BP lowering effects of HF medication. Regarding BP variability and variations, beyond the lack of significant differences between the two groups, we noticed a severely blunted systolic and diastolic diurnal index in both groups, with smaller values in the group with more severe SA, phenomena which could be explained by the HF-related autonomic imbalance (sympathetic overactivity and decreased vagal control), which is further augmented by the presence of SA. The latter mechanism could also explain the relatively higher $\mathrm{BP}$ values in the group of patients with more severe SA [11, 12]. This finding could have a double significance: one negative (the higher left ventricular afterload) and one positive (the more BP "reserve" for uptitration of cardioactive medication). The relatively little data in the literature dealing with 24-hour BP monitoring in patients with $\mathrm{HF}$, although the studies are heterogeneous regarding the study populations, support our results: generally, low BP values are associated with blunted circadian variation [16-18]. Moreover, BP values and circadian BP behavior-related parameters were found to have prognostic value in patients with $\operatorname{HF}[19,20]$.

The increase in incidence of nocturnal arrhythmias has been described in the setting of significant SA in various categories of patients, including those with HF [21, 22]. In the seminal Sleep Heart Health Study, after adjusting the results for age, sex, body mass index, and the presence of coronary artery disease, the risk for atrial fibrillation and ventricular ectopy was significantly greater in patients with more severe obstructive SA [23]. In a longitudinal study on 10,701 adults, during a 5-year follow-up period, the incidence of sudden cardiac death was directly related to the severity of SA and nocturnal oxygen de- saturation [24]. In a large cohort $(n=2,911)$ of elderly men, the more severe forms of SA were associated with increased incidence of atrial fibrillation (mostly in the case of central forms - this tendency being present also in patients with $\mathrm{HF}$ ) and complex ventricular ectopy (mostly in the case of obstructive forms) [25].

In a study recruiting 81 ambulatory men with stable HF, those patients with SA had significantly more episodes of atrial fibrillation and a higher number of premature ventricular depolarizations [26]. Furthermore, many other studies support the increased incidence of malignant ventricular arrhythmias and sudden cardiac death, especially during nighttime, in patients with $\mathrm{HF}$ and comorbid SA [27, 28].

Bradyarrhythmias (including asystole and 2nd and 3rd degree AV blocks) are related primarily to apneas. Prolonged apneas cause hypoxemia, which, by increasing the activity of peripheral chemoreceptors, triggers an enhanced vagal tone in the absence of ventilation. The mechanisms and factors behind SA-related tachyarrhythmias are more complex: hypoxemia together with myocardial ischemia, autonomic triggers (sympathetic overactivity caused by arousals), parietal stretch induced by negative intrathoracic pressure in the case of obstructive SA, and chronic cardiac structural alterations. Specifically, ventricular arrhythmias and nocturnal atrial fibrillation paroxysms, including recurrences after successful cardioversion, are characteristic in this regard [29].

Our study population consisted of patients with already stabilized AHF, and the general prevalence of arrhythmias (bradycardias and ectopy) was relatively low. In the group with more severe SA, we observed a slightly lower decrease of nocturnal heart rate, and an increased number of nighttime (vs. diurnal) ventricular and supraventricular ectopies. The lack of a striking difference between the two groups could have many explanations: e.g., sample size, current use of betablockers, already reaching a stable clinical condition, etc. However, the blunted circadian variation of heart rate in the group with more severe SA could herald a poorer prognosis [30]. The twotime domain HRV parameters had low values, as expected for patients with systolic HF [12].

\section{Conclusion}

Our study is a contribution to the understanding of the importance of SA in the setting of HFs. We assessed the influence of SA on 24-hour and nocturnal BP, heart 
rate, and rhythm behavior, as these variables have important therapeutic and prognostic implications. Our results confirmed significantly higher $\mathrm{BP}$ values and more nocturnal ectopic activity in stable AHF patients with more severe SA. Although, these findings suggest an increased risk in these patients, their potential clinical value has to be determined on a larger patient population. Routine use of 24-hour BP monitoring could have a similar practical value in the setting of HF (both acute and chronic) as Holter ECG monitoring: fine-tuning of therapy on the basis of BP values and using parameters of $\mathrm{BP}$ variability and circadian variation for prognostic purposes.

\section{Acknowledgements}

The study was supported by Grant No. 15276/03.11.2015, with private financing of the University of Medicine and Pharmacy of Tirgu Mures, Tirgu Mures, Romania.

\section{Statement of Ethics}

This study received approval of the Ethical Committee of the Clinical County Hospital Mures (No. 3865/01.03.2016).

\section{Disclosure Statement}

The authors have no conflicts of interest to declare.

\section{References}

1 Ponikowski P, Voors AA, Anker SD, Bueno $\mathrm{H}$, Cleland JG, Coats AJ, et al.; Authors/Task Force Members; Document Reviewers. 2016 ESC Guidelines for the diagnosis and treatment of acute and chronic heart failure: the Task Force for the diagnosis and treatment of acute and chronic heart failure of the European Society of Cardiology (ESC). Developed with the special contribution of the Heart Failure Association (HFA) of the ESC. Eur J Heart Fail. 2016 Aug;18(8):891-975.

2 Packer M. Acute heart failure is an event rather than a disease: plea for a radical change in thinking and in therapeutic drug development. JACC Heart Fail. 2018 Jan;6(1):73-5.

3 Linz D, Woehrle H, Bitter T, Fox H, Cowie MR, Böhm M, et al. The importance of sleepdisordered breathing in cardiovascular disease. Clin Res Cardiol. 2015 Sep;104(9):70518.

4 Berry RB, Brooks R, Gamaldo CE, et al.; American Academy of Sleep Medicine. The AASM Manual for the Scoring of Sleep and Associated Events: Rules, Terminology and Technical Specifications. Version 2.4. Darien (Illinois): American Academy of Sleep Medicine; 2017.

5 Kapur VK, Auckley DH, Chowdhuri S, Kuhlmann DC, Mehra R, Ramar K, et al. Clinical practice guideline for diagnostic testing for adult obstructive sleep apnea: an American Academy of Sleep Medicine clinical practice guideline. J Clin Sleep Med. 2017 Mar;13(3): 479-504.

6 Oldenburg O, Lamp B, Faber L, Teschler H, Horstkotte D, Töpfer V. Sleep-disordered breathing in patients with symptomatic heart failure: a contemporary study of prevalence in and characteristics of 700 patients. Eur J Heart Fail. 2007 Mar;9(3):251-7.
7 Bitter T, Faber L, Hering D, Langer C, Horstkotte D, Oldenburg O. Sleep-disordered breathing in heart failure with normal left ventricular ejection fraction. Eur J Heart Fail. 2009 Jun;11(6):602-8.

8 Adar A, Kırış A, Bülbül Y, Bektaş H, Acat M, Casim $\mathrm{H}$, et al. Association of fragmented QRS with subclinical left ventricular dysfunction in patients with obstructive sleep apnea. Med Princ Pract. 2015;24(4):376-81.

9 Yumino D, Redolfi S, Ruttanaumpawan P, Su MC, Smith S, Newton GE, et al. Nocturnal rostral fluid shift: a unifying concept for the pathogenesis of obstructive and central sleep apnea in men with heart failure. Circulation. 2010 Apr;121(14):1598-605.

10 Drager LF, McEvoy RD, Barbe F, Lorenzi-Filho G, Redline S; INCOSACT Initiative (International Collaboration of Sleep Apnea Cardiovascular Trialists). Sleep apnea and cardiovascular disease: lessons from recent trials and need for team science. Circulation. 2017 Nov;136(19):1840-50.

11 Cowie MR, Gallagher AM. Sleep disordered breathing and heart failure: what does the future hold? JACC Heart Fail. 2017 Oct;5(10): 715-23.

12 Pearse SG, Cowie MR. Sleep-disordered breathing in heart failure. Eur J Heart Fail. 2016 Apr;18(4):353-61.

13 Khayat R, Abraham W, Patt B, Brinkman V, Wannemacher J, Porter K, et al. Central sleep apnea is a predictor of cardiac readmission in hospitalized patients with systolic heart failure. J Card Fail. 2012 Jul;18(7):534-40.

14 Khayat R, Jarjoura D, Porter K, Sow A, Wannemacher J, Dohar R, et al. Sleep disordered breathing and post-discharge mortality in patients with acute heart failure. Eur Heart J. 2015 Jun;36(23):1463-9.
15 Cai A, Wang L, Zhou Y. Hypertension and obstructive sleep apnea. Hypertens Res. 2016 Jun;39(6):391-5.

16 Goyal D, Macfadyen RJ, Watson RD, Lip GY. Ambulatory blood pressure monitoring in heart failure: a systematic review. Eur J Heart Fail. 2005 Mar;7(2):149-56.

17 Mallion JM, Neuder Y, Ormezzano O, Rochette GB, Salvat M, Baguet JP. Study of nycthemeral variations in blood pressure in patients with heart failure. Blood Press Monit. 2008 Jun;13(3):163-5.

18 van de Borne P, Abramowicz M, Degre S, Degaute JP. Effects of chronic congestive heart failure on 24-hour blood pressure and heart rate patterns: a hemodynamic approach. Am Heart J. 1992 Apr;123(4 Pt 1):998-1004.

19 Canesin MF, Giorgi D, Oliveira MT Jr, Wajngarten M, Mansur AJ, Ramires JA, et al. Ambulatory blood pressure monitoring of patients with heart failure. A new prognosis marker. Arq Bras Cardiol. 2002 Jan;78(1):839.

20 K K, Bagarhatta R, Rathore M, Bagarhatta P. Is ambulatory blood pressure measurement a new indicator for survival among advanced heart failure cases? Indian Heart J. 2018;70 Suppl 1: S73-S78. https://doi.org/10.1016/j. ihj.2017.08.028.

21 Hersi AS. Sleep-related breathing disorders and cardiac arrhythmia. In: Breijo-Marquez F, editor. Cardiac arrhythmias - New considerations. Rijeka: IntechOpen; 2012. pp. 26788.

22 Bitter T, Fox H, Gaddam S, Horstkotte D, Oldenburg O. Sleep-disordered breathing and cardiac arrhythmias. Can J Cardiol. 2015 Jul;31(7):928-34. 
23 Mehra R, Benjamin EJ, Shahar E, Gottlieb DJ, Nawabit R, Kirchner HL, et al.; Sleep Heart Health Study. Association of nocturnal arrhythmias with sleep-disordered breathing: The Sleep Heart Health Study. Am J Respir Crit Care Med. 2006 Apr;173(8):910-6.

24 Gami AS, Olson EJ, Shen WK, Wright RS, Ballman KV, Hodge DO, et al. Obstructive sleep apnea and the risk of sudden cardiac death: a longitudinal study of 10,701 adults. J Am Coll Cardiol. 2013 Aug;62(7):610-6.

25 Mehra R, Stone KL, Varosy PD, Hoffman AR, Marcus GM, Blackwell T, et al. Nocturnal Arrhythmias across a spectrum of obstructive and central sleep-disordered breathing in older men: outcomes of sleep disorders in older men (MrOS sleep) study. Arch Intern Med. 2009 Jun;169(12):1147-55.

26 Javaheri S, Parker TJ, Liming JD, Corbett WS, Nishiyama H, Wexler L, et al. Sleep apnea in 81 ambulatory male patients with stable heart failure. Types and their prevalences, consequences, and presentations. Circulation. 1998 Jun;97(21):2154-9.

27 Bitter T, Westerheide N, Prinz C, Hossain MS, Vogt J, Langer C, et al. Cheyne-Stokes respiration and obstructive sleep apnoea are independent risk factors for malignant ventricular arrhythmias requiring appropriate cardioverter-defibrillator therapies in patients with congestive heart failure. Eur Heart J. 2011 Jan;32(1):61-74.
28 Bitter T, Fox H, Dimitriadis Z, Niedermeyer J, Prib N, Prinz C, et al. Circadian variation of defibrillator shocks in patients with chronic heart failure: the impact of Cheyne-Stokes respiration and obstructive sleep apnea. Int $J$ Cardiol. 2014 Oct;176(3):1033-5.

29 Leung RS. Sleep-disordered breathing: autonomic mechanisms and arrhythmias. Prog Cardiovasc Dis. 2009 Jan-Feb;51(4):324-38.

30 Arsenos P, Gatzoulis KA, Gialernios T, Dilaveris $\mathrm{P}$, Tsiachris D, Archontakis S, et al. Elevated nighttime heart rate due to insufficient circadian adaptation detects heart failure patients prone for malignant ventricular arrhythmias. Int J Cardiol. 2014;172(1):e1546. 